Review

\title{
Cutaneous Adverse Reactions Associated with SARS-CoV-2 Vaccines
}

\author{
Francesco Bellinato *(D), Martina Maurelli (D), Paolo Gisondi (D) and Giampiero Girolomoni
}

Citation: Bellinato, F.; Maurelli, M.; Gisondi, P.; Girolomoni, G. Cutaneous Adverse Reactions Associated with SARS-CoV-2 Vaccines. J. Clin. Med. 2021, 10, 5344. https://doi.org/10.3390/jcm10225344

Academic Editor: Masutaka Furue

Received: 28 October 2021

Accepted: 13 November 2021

Published: 16 November 2021

Publisher's Note: MDPI stays neutral with regard to jurisdictional claims in published maps and institutional affiliations.

Copyright: (c) 2021 by the authors. Licensee MDPI, Basel, Switzerland. This article is an open access article distributed under the terms and conditions of the Creative Commons Attribution (CC BY) license (https:// creativecommons.org/licenses/by/ $4.0 /)$.
Section of Dermatology and Venereology, Department of Medicine, University of Verona, Piazzale A. Stefani 1, 37126 Verona, Italy; maurelli.martina@gmail.com (M.M.); paolo.gisondi@univr.it (P.G.); giampiero.girolomoni@univr.it (G.G.)

* Correspondence: francesco.bellinato@univr.it
Abstract: Many patients are receiving SARS-CoV-2 vaccinations, which have been associated with a variety of adverse effects. Cutaneous adverse reactions to SARS-CoV-2 vaccinations have been progressively reported, but they have not been reviewed according to their morphological clinical patterns. The objective of this review was to summarize the existing data concerning the cutaneous adverse reactions following SARS-CoV-2 vaccines and group them according to common morphological and pathogenetic patterns. We reviewed the English language literature up to 15 August 2021, using predefined keywords to identify the relevant studies evaluating cutaneous adverse reactions associated with SARS-CoV-2 vaccines. We search for recurrent morphological patterns sharing clinical signs and symptoms and physio-pathological mechanisms. Timing to onset following the first or booster dose of the vaccine, predisposing conditions, therapeutic management, and outcome were also collected. Among the dermatological manifestations associated with SARS-CoV-2 vaccinations, we distinguished: (1) new onset reactions and (2) flares of preexisting dermatoses. The most common were injection site reactions, affecting 30-70\% and generally mild or moderate. Small case series or single case reports included filler reactions, exanthemas, vascular lesions, urticaria, eczematous dermatitis, autoimmune bullous reactions, and severe cutaneous adverse reactions. In addition, the exacerbation of chronic immuno-mediated dermatoses (mainly psoriasis and atopic dermatitis) and reactivations of herpes infection were reported. The cutaneous reactions were generally mild, self-limiting, and resembled common cutaneous drug eruptions and/or COVID-19 skin manifestations.

Keywords: vaccines; COVID-19; cutaneous adverse reaction; exanthema; safety

\section{Introduction}

To stem the severe acute respiratory syndrome coronavirus 2 (SARS-CoV-2) pandemic, a very large vaccination campaign is spreading widely. A massive number of individuals are going to receive vaccinations globally. Different strategies are being explored as possible vaccines against SARS-CoV-2, including inactivated virus vaccines, virus-like particle or nanoparticle vaccines, protein subunit vaccines, virus-vectored vaccines, DNA and messenger RNA (mRNA) vaccines, and live-attenuated virus vaccines [1]. Single-stranded RNA (ssRNA) and double-stranded RNA (dsRNA) act as potent inflammatory signals. Upon inoculation, they are recognized by various endosomal and cytosolic innate sensors (i.e., TLR3, TLR7, and components of the inflammasome), resulting in cellular activation, the production of type I interferon, and multiple inflammatory mediators [2]. The potency of mRNA vaccines has been optimized by the encapsulation of the mRNA into lipidic nanoparticles, called LNPs, throughout the protection of the mRNA from degradation by RNase enzymes. The intramuscular administration of LNP-formulated mRNA vaccines results in local and transient inflammation in the muscle, which drives the recruitment of neutrophils and antigen-presenting cells (APCs) to the site of delivery [3]. Two mRNA 
(Pfizer/BioNTech BNT162b2 and Moderna mRNA-1273) and two adenovirus-vectored (AstraZeneca/Oxford AZD1222 and Johnson \& Johnson/Janssen Ad26.CoV2.S) vaccines have already received conditional marketing authorization by the European Medical Agency (EMA). Control for vaccine safety requires a proactive approach, involving vigilance, response, documentation, and characterization of the events [4]. Cutaneous manifestations following vaccinations are not uncommon. As a consequence, a significant number of adverse skin reactions are expected to develop [5]. When several individuals will be immunized in mass vaccinations campaigns, even rare adverse events might be encountered more often. Clinicians should be prepared to address dermatological reactions (local and systemic) to SARS-CoV-2 vaccinations. The objective of this review was to summarize the existing data concerning the cutaneous adverse reactions following SARS-CoV-2 vaccines and group them according to common morphological and pathogenetic patterns.

\section{Materials and Methods}

We carried out a narrative review of the English language literature related to any cutaneous adverse reactions attributed to SARS-CoV-2 vaccines. The terms used for the PubMed search were as follows: "COVID-19 Vaccine*" OR "SARS-CoV-2 Vaccination" AND "Skin*" OR "Cutaneous*" OR "delayed*" OR "dermatology*" OR "vesiculo*" AND "reaction*" OR "effect*" OR "event" OR "Eruption" ${ }^{*}$ " OR "rash" OR "flares*" OR "eczema*" OR "lesion*" OR "pemphigus*" OR "psoriasis*", NOT "thrombocytopenia*" OR "cardiological $^{* "}$ OR "neurological*" OR "myocarditis*" OR "thromboembolic"*. The search included original articles (i.e., case reports, case series, registry-based observational studies, and randomized controlled trials) published from 31 March 2020 (inception date) to 15 August 2021.

There were no restrictions in terms of sex, race, or geographic area. Additionally, we reviewed references from relevant original papers and review articles to identify further eligible studies not covered by the original database search. Studies describing clinical cutaneous adverse reactions after at least one dose of mRNA (Pfizer/BioNTech BNT162b2 and Moderna mRNA-1273) or adenovirus-vectored (AstraZeneca/Oxford AZD1222 and Johnson \& Johnson/Janssen Ad26.CoV2.S) SARS-CoV-2 vaccine were included. In the manuscripts, the association between cutaneous adverse reactions and SARS-CoV-2 vaccinations was supported by temporal and topographical criteria, the lack of any other trigger factors (i.e., infections or new medications), recurrence with the booster, previous published reports, and/or biological plausibility. The criteria for exclusion were as follows: (1) studies that did not have a clear morphologic description of the dermatologic signs and /or symptoms in their clinical presentations; (2) studies involving pediatric populations; (3) articles written in a language other than English; and (4) review articles, conference abstracts, and expert opinions. For all eligible studies, the following data were retrieved: authors and year of publication; study country; study design; sample size; population characteristics (age, sex, preexisting dermatologic, and/or allergic conditions); type of cutaneous reactions; timing to onset following the first or booster dose of the vaccine; histopathological assessment; therapeutic management; and outcome. To illustrate the clinical appearance of the patterns, the pictures of the original cases observed in our clinical practice were included.

\section{Results}

A total of 226 articles were identified through PubMed Medline ${ }^{\circledR}$. After screening through the titles and abstracts, 151 articles were excluded because they were not pertinent. A total of 107 articles underwent full-text assessments for eligibility, and 33 articles were excluded based on the exclusion/inclusion criteria. Finally, a total of 74 studies were included in the review (Figure 1). 


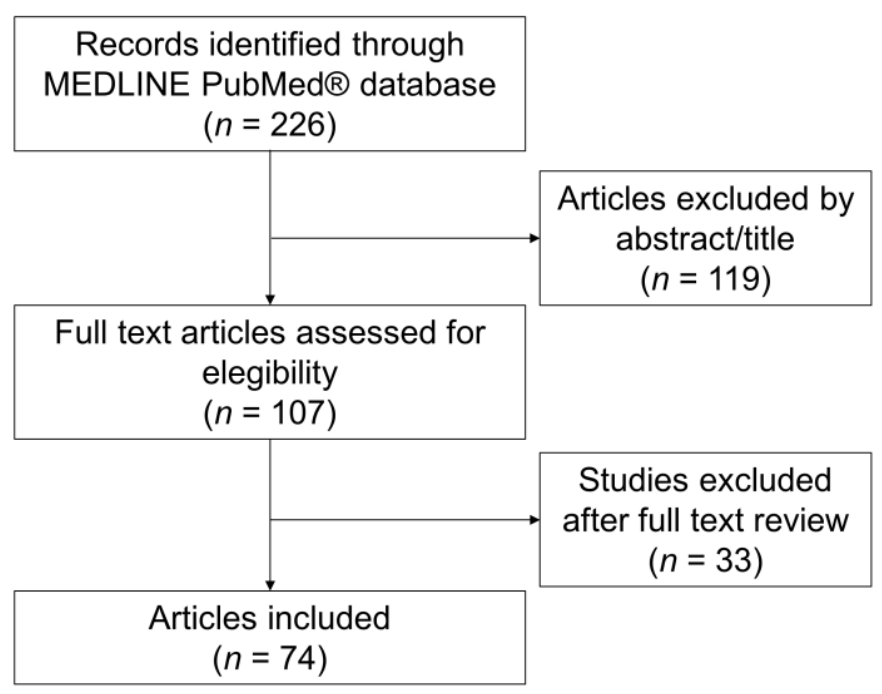

Figure 1. Screening flow chart.

We classified the cutaneous adverse reactions associated with SARS-CoV-2 vaccinations into two groups: (1) new onset skin reactions and (2) flares of preexisting dermatoses. Among the former, we classified cutaneous reactions in different patterns sharing morphological and pathogenetic mechanisms as follows: injection site reactions (immediate and delayed local reactions/COVID arm); filler reactions; exanthemas (confluent erythematous rash, morbilliform or maculopapular, varicelliform or papulovesicular, pityriasis rosea/pityriasis rosea-like, symmetrical drug-related intertriginous and flexural exanthema (SDRIFE), and annular); urticaria (wheals and/or angioedema); vascular lesions (vasculitis, purpura/petechiae, livedo, acral chilblain-like, and erythromelalgia); eczematous dermatitis; autoimmune bullous diseases; and severe cutaneous adverse reactions (SCARs), including acute generalized exanthematous pustulosis (AGEP) and Stevens-Johnson syndrome/Toxic Epidermal Necrolysis (SIS/TEN). Each pattern is described below (Table 1).

\subsection{Characteristics of Subjects Developing Cutaneous Adverse Reactions}

According to the data retrieved from a large registry-based study and a national cross-sectional study, involving 819 reactions in 805 patients overall, adverse cutaneous reactions associated with SARS-CoV-2 vaccinations are more frequent among females than males, ranging from $80 \%$ to $90 \%$ of the reported cases [6,7]. Generally, cutaneous reactions are slightly more common after the first dose compared to the booster (53\% vs. $46 \%$, respectively) [6]. Recurrence after booster inoculation was reported in a proportion ranging from $8 \%$ to $46 \%$ of the patients who experienced a reaction after the first dose. In particular, Català et al. found that $8.5 \%$ (14) of patients with first dose reactions developed a second dose reaction, and in seven of them, it was the same [6]. The mean time to onset after the vaccination ranges from immediate reactions, occurring within hours after inoculation, to some weeks, as it might depend on several variables (type and dose of vaccine, immunological state, history of COVID-19, comorbidities, etc.). In these two large studies, the proportion of cases with a history of atopic dermatitis and chronic urticaria was low compared to the general population $(4.1-6.9 \%$ vs. $10 \%$ and $1.7-6.4 \%$ vs. $20 \%$, respectively), suggesting that such conditions may not predispose toward cutaneous adverse reactions, as is well-established for cutaneous drug reactions in general $[6,7]$. 
Table 1. Patterns of new onset adverse skin reactions associated with SARS-CoV-2 vaccinations.

\begin{tabular}{|c|c|c|}
\hline Pattern & Subtype & $\begin{array}{l}\text { Reported Associated } \\
\text { Vaccines }\end{array}$ \\
\hline Injection site reactions & $\begin{array}{l}\text { Immediate local reaction } \\
\text { Delayed local reaction }\end{array}$ & All \\
\hline Filler reactions & - & Pfizer/BioNTech, Moderna \\
\hline \multirow{4}{*}{ Exanthemas } & $\begin{array}{c}\text { Erythematous confluent } \\
\text { Maculopapular } \\
\text { Papulovesicular }\end{array}$ & All \\
\hline & Pityriasis rosea like & $\begin{array}{l}\text { Pfizer/BioNTech, Moderna, } \\
\text { AstraZeneca/Oxford }\end{array}$ \\
\hline & SDRIFE & Pfizer/BioNTech \\
\hline & Annular & Johnson \& Johnson/Janssen \\
\hline \multirow{6}{*}{ Vascular lesions } & Leucocytoclasic vasculitis & All \\
\hline & Urticarial vasculitis & Pfizer/BioNTech \\
\hline & Purpura/petechiae & All \\
\hline & Livedo racemosa & Pfizer/BioNTech \\
\hline & Chilblain-like & Pfizer/BioNTech, Moderna \\
\hline & Erythromelalgia & Pfizer/BioNTech, Moderna \\
\hline Urticaria & Wheals and/or angioedema & $\begin{array}{c}\text { Pfizer/BioNTech, Moderna, } \\
\text { AstraZeneca/Oxford }\end{array}$ \\
\hline Eczematous dermatitis & - & Pfizer/BioNTech, Moderna \\
\hline \multirow{2}{*}{$\begin{array}{l}\text { Autoimmune bullous } \\
\text { reactions }\end{array}$} & $\begin{array}{l}\text { Subepidermal bullous } \\
\text { diseases }\end{array}$ & Pfizer/BioNTech, Moderna \\
\hline & Pemphigus & Pfizer/BioNTech \\
\hline \multirow{5}{*}{ SCARs } & AGEP & AstraZeneca/Oxford \\
\hline & DRESS & Johnson \& Johnson/Janssen \\
\hline & SJS/TEN & $\begin{array}{c}\text { Pfizer/BioNTech, } \\
\text { AstraZeneca/Oxford }\end{array}$ \\
\hline & EM major & Moderna \\
\hline & Extensive FDE & Moderna \\
\hline \multirow{4}{*}{ Other dermatoses } & Sweet syndrome & Moderna \\
\hline & Rosacea-like eruption & $\begin{array}{c}\text { Pfizer/BioNTech, Johnson \& } \\
\text { Johnson/Janssen }\end{array}$ \\
\hline & $\begin{array}{c}\text { Psoriasis (plaque, guttate, } \\
\text { palmoplantar, and generalized } \\
\text { pustular) }\end{array}$ & $\begin{array}{l}\text { Pfizer/BioNTech, Moderna, } \\
\text { Johnson \& Johnson/Janssen }\end{array}$ \\
\hline & $\begin{array}{c}\text { Pityriasis rubra pilaris-like } \\
\text { eruption }\end{array}$ & Pfizer/BioNTech \\
\hline
\end{tabular}

\subsection{Injection Site Reactions}

Both immediate and delayed local reactions are extremely common. For example, in a national cross-sectional study involving a total of 415 cutaneous reactions, Català et al. found that $32.1 \%$ (130) were injection site reactions, of which $53.8 \%$ were delayed [6]. Immediate and delayed local reactions represented $52.4 \%$ (232) and $49.2 \%$ (218) of a large registry-based study of 443 reactions, respectively [7]. Tenderness, itchiness, erythema, and swelling may develop immediately up to a few days after inoculation (Figure 2A,B) [8,9]. Delayed reactions, occurring some days after vaccination, are even more common, representing more than half of the local reactions [6]. Similar findings were confirmed in Black, Indigenous, or People of Color [10]. The so-called COVID arm is an erythematous, indurated, edematous, itchy, or painful plaque of different sizes developing in the area where the vaccine was inoculated [11,12]. Necrotic lesions characterized by angulated 
eschars surrounded by indurated erythematous borders at site of inoculation were reported one week after BNT162b2 vaccination [13]. The mean time to onset ranges from 4 to 11 days from the first $[7,8,14]$ and 2-5 days from the second dose [7]. The COVID arm can recur with the booster but is, on average, likely to be less severe and may develop faster [7]. In the case of fever, the suspect of cellulitis should be ruled out [12]. Histopathology shows a superficial and deep perivascular lymphocytic infiltrate with dilated vessels, intraluminal neutrophils, and negative immunohistochemistry for the SARS-CoV-2 spike protein, consistent with delayed-type or T-cell-mediated hypersensitivity reactions [12]. Symptomatic therapies as antihistamines and/or topical glucocorticoids can be used for treatment, as for drug-induced injection site reactions [14,15]. No serious adverse reactions have been reported after the second dose. Burning bullous reactions have been observed after the application of an ice pack for a relief from pain (Figure 2C). Pigmentary changes (hyper or hypo) may follow the acute phase, especially after more severe reactions (Figure 2D).
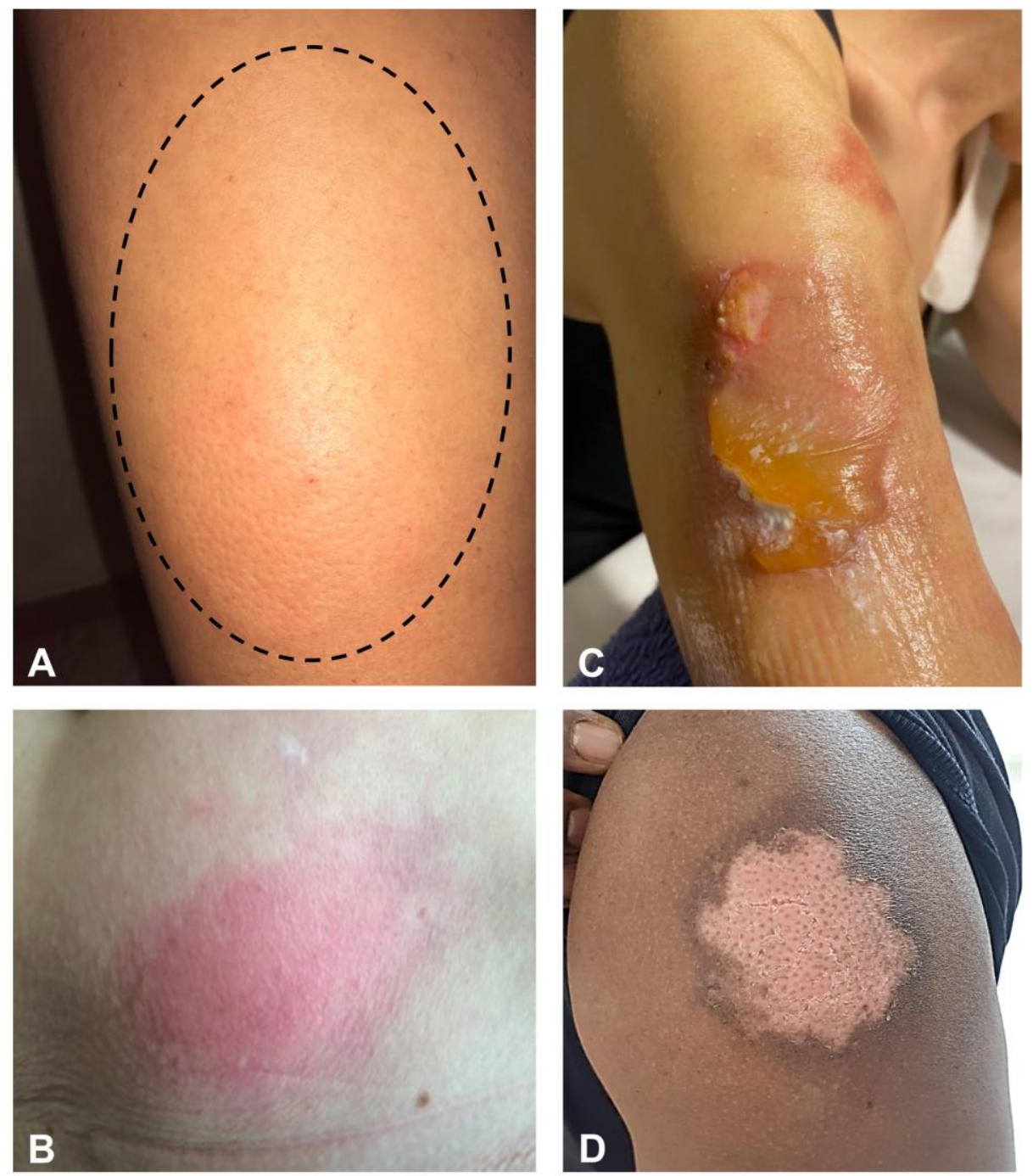

Figure 2. Edematous (A) and erythematous (B) indurated and tender plaques in the site of the injection developed one week after BNT162b2 vaccination in 36- and 67-year-old females, respectively. Burning bullous reactions on the deltoid area after the application of an ice pack to relieve the pain in a 56-year-old woman (C). Depigmented erythematous plaque of the deltoid skin developed in a 39-year-old African man three weeks after BNT162b2 vaccination (D). 


\subsection{Filler Reactions}

Interestingly, unusual delayed inflammatory reactions to dermal hyaluronic acid filler employed for aesthetics were described both following COVID-19 infection and mRNA vaccinations. The clinical presentation is characterized by slightly erythematous, soft, and tender swelling of the filler injection site $[7,16,17]$. Filler reactions can be auto-resolutive or symptomatic, requiring hyaluronidase injections and systemic glucocorticosteroids. Since a potential pathophysiologic mechanism of filler reactions is the binding of spike protein with dermal ACE2 receptors, some authors have treated this reaction with low-dose angiotensin-converting enzyme inhibitors to reduce proinflammatory angiotensin II [14].

\subsection{Exanthemas}

Exanthemas following SARS-CoV-2 vaccination can develop either as a pruritic confluent erythematous or maculopapular morbilliform eruption generally involving the face, the trunk, and the limbs in a bilateral and symmetrical fashion with a typical craniocaudal progression (Figure 3). Histopathology has revealed classical findings, i.e., mixed-cell infiltrate with eosinophils, epidermal spongiosis, keratinocyte apoptosis, and vacuolar interface changes [6]. Pruritus may be severe. A purpuric hue can be found, especially when the rash involves the inferior limbs [18-23]. A -papulovesicular or varicelliform rash is characterized by small papules/vesicles surrounded by erythema without a herpetiform arrangement [6]. In a large cross-sectional study involving a total of 415 cutaneous reactions, the prevalence of morbilliform and papulovesicular rashes was $8.9 \%$ (36) and $6.4 \%$ (26), respectively [6]. McMohan et al. observed similar proportions, reporting a prevalence of $6.1 \%$ (27 out of 443 ) morbilliform and $8.3 \%$ (10 out of 443 ) papulovesicular rashes, respectively [7]. The maculopapular rash develops in almost $70 \%$ of cases after the first dose, with a timing to onset ranging from two days to two weeks [6]. In a large prospective cohort study of almost 50,000 health employees who received mRNA vaccines, itchy exanthema was the most common cutaneous reaction, reported by $1.5 \%$ of the patients after the first dose and $1.6 \%$ after the second [8]. In a randomized, cross-sectional study of 803 patients after BNT162b2 vaccination, the self-reported prevalence of exanthema was $2.5 \%$ [24]. Recurrence occurred in $16 \%$ of those who experienced the first reaction. Exanthema reactions can be easily treated with systemic and/or topical corticosteroid and systemic antihistamines to relieve symptoms and shorten the disease duration $[20,21]$. We also observed the occurrence of uncommon rashes as SDRIFE (Figure 4). Rarely, an extensive erythematous rash with blistering evolution may occur [25]. Atypical rashes reminiscent of pityriasis rosea following 4-7 days after mRNA vaccination have also been reported $[6,7,19,20,25,26]$. Unlike pityriasis rosea, these reactions are characterized by more itchy and diffuse lesions with a more frequent involvement of mucous membranes and no preceding herald patch [27]. It is still not clear whether pityriasis rosea-like exanthema is secondary to the direct invasion of SARS-CoV-2 or HHV-6/7 reactivation [27]. One case of figurate annular eruption following Ad26.CoV2.S vaccine was also reported [28]. 

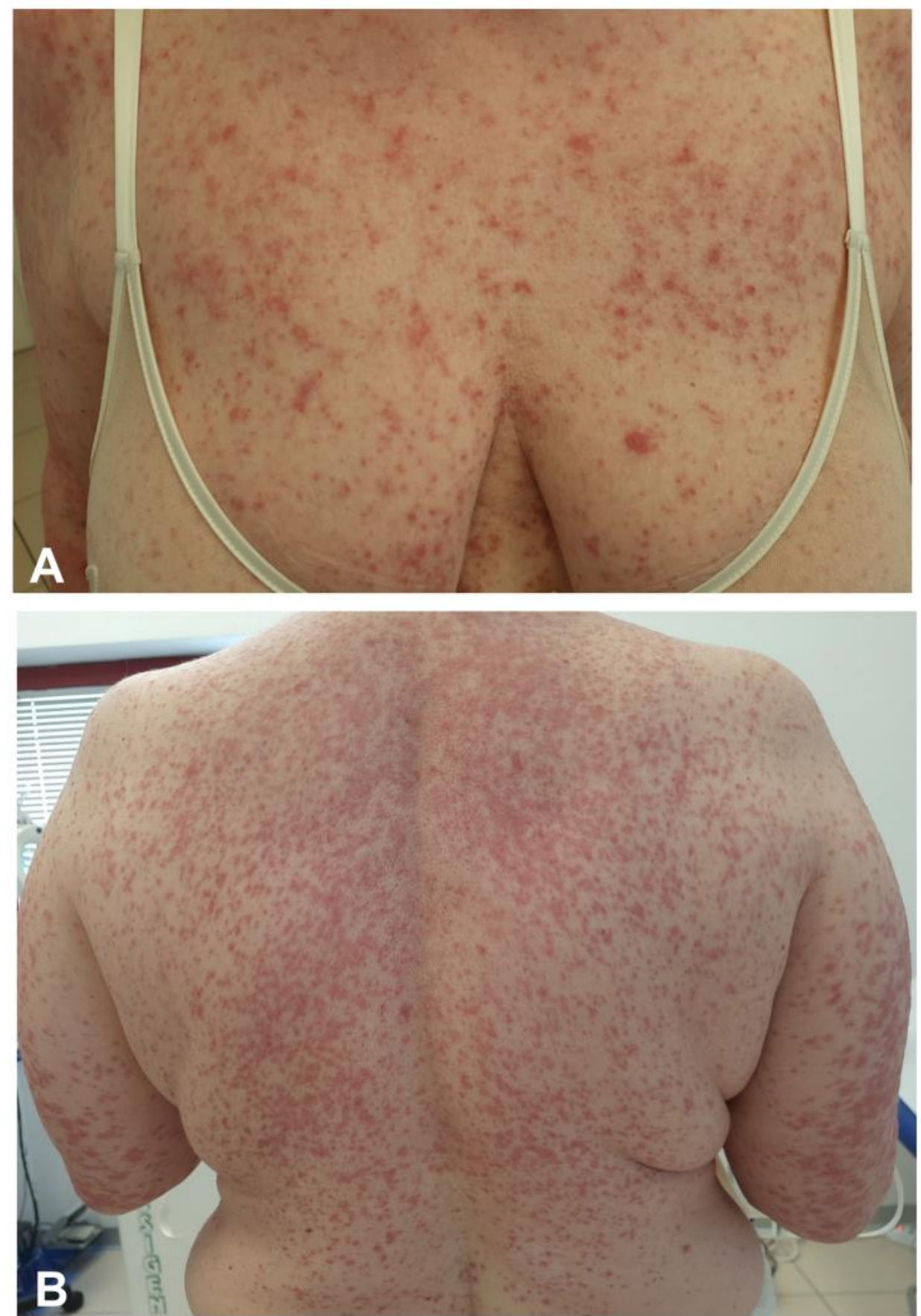

Figure 3. Itchy confluent erythematous maculopapular eruption involving the upper trunk and limbs in a bilateral and symmetrical fashion and typical craniocaudal progression developed five days after the mRNA-1273 vaccine on a 54-year-old woman (A,B). 

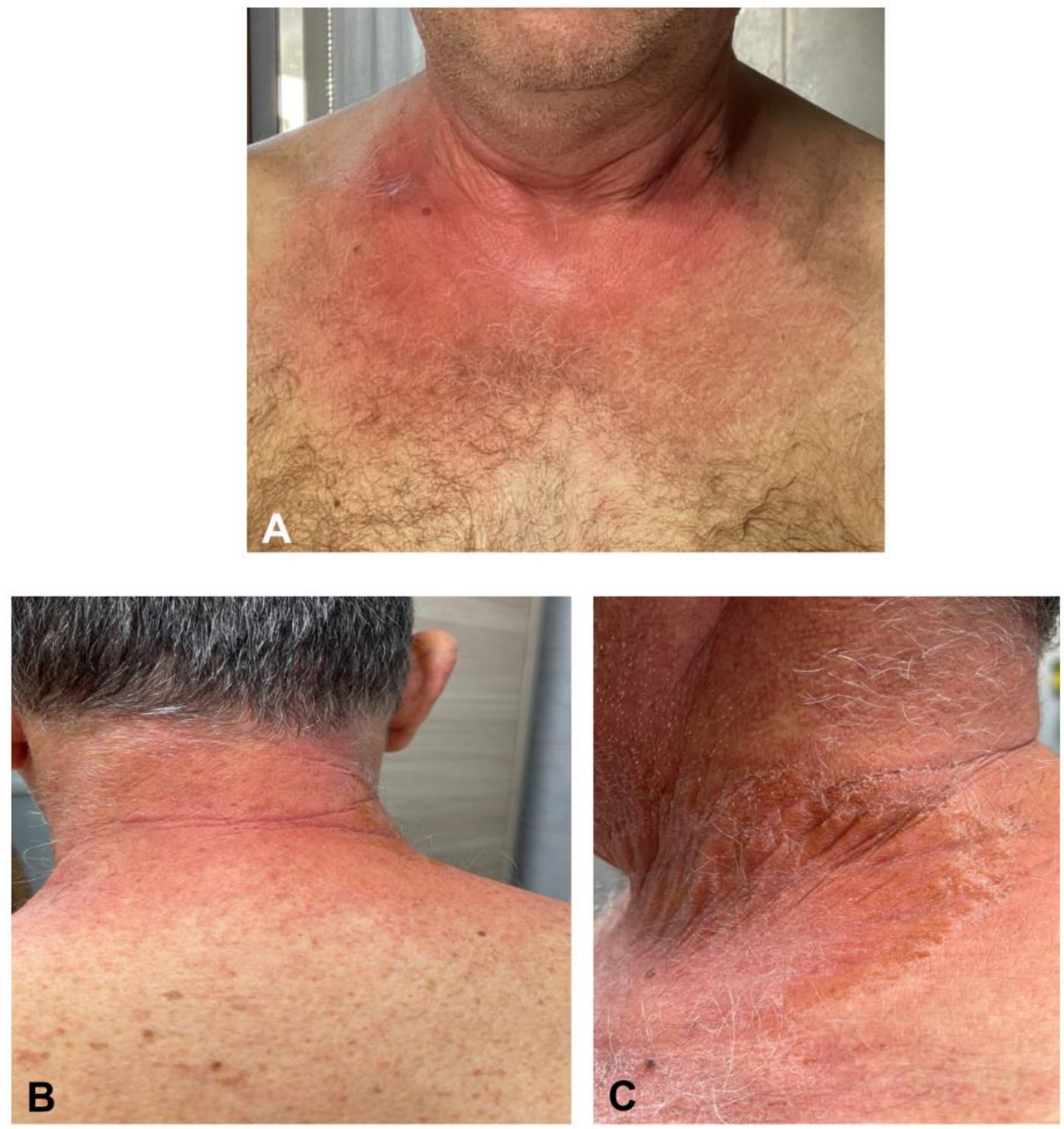

Figure 4. Erythematous and sharply demarcated lesions with symmetric and intertriginous-flexural distribution involving the neck and the gluteal area (symmetrical drug-related intertriginous and flexural exanthema-SDRIFE) developed on a 65-year-old physician two weeks after the BNT162b2 vaccine $(\mathbf{A}-\mathbf{C})$.

\subsection{Vascular Lesions}

Distinct types of vascular skin lesions have been described, including leucocytoclastic vasculitis, purpura/petechiae, livedo, chilblain-like lesions, and erythromelalgia.

Cases of cutaneous leukocytoclastic vasculitis were described following both the first and booster doses of mRNA and adenovirus-vectored vaccinations, including vasculitis urticaria $[6,7,9,29,30]$. In a national cross-sectional study involving a total of 415 cutaneous reactions, Català et al. found that $4 \%(n=16)$ were a purpuric rash of the lower limbs, of which four were cutaneous leukocytoclastic vasculitis [6]. The clinical presentation showed the typical features of cutaneous small-vessel vasculitis, including confluent palpable purpura lesions in the buttocks, legs, lower portion of the abdomen, and arms. The histopathological findings included perivascular and interstitial neutrophilic infiltrate with leukocytoclasia and fibrin deposition within vessel walls $[20,30]$. The time to onset ranged from 2 to 7 days after vaccine inoculation. The new onset of urticarial vasculitis was also described 5 days following a second dose of the BNT162b2 vaccine [23]. Small-vessel vasculitis has been described after several vaccination types-in particular, the influenza vaccine [31]. 
Improvement of the lesions can be obtained after a course of systemic and topical glucocorticosteroids. Petechial eruptions were described as a possible consequence of immune thrombocytopenic purpura following mRNA vaccination. Some cases were accompanied by systemic signs/symptoms like weakness, shortness of breath, leg edema, nausea, vomiting, and abdominal pain [32-34]. A petechial rash of the trunk was even reported in a patient with anaphylactic symptoms [35]. Other forms of purpuric/petechial lesions can be the expression of eczematous pigmented purpura [6] or presenting as an asymptomatic purpura of the eyelid [36] or a brownish rust-like macular erythema of the hands, possibly due to hemosiderin deposition [37]. Purpura can also be arranged in "whip-like" linear or curvilinear streaks as purpura flagellate [38]. Livedo racemosa of the thighs is another vascular presentation following the mRNA vaccine [18].

Sars-CoV-2 vaccine-related chilblain-like lesions are painful and have itching violaceous nodules in acral sites (toes and hands) resembling pernio and COVID toe. Chilblainlike lesions can develop in 4-12 days after the first dose of mRNA or inactivated SARSCoV-2 vaccines (CoronaVac by Sinovac Life Sciences) [6,19,23,39-41]. Topical glucocorticosteroids and antihistamines have been used with success [23].

Interestingly, erythromelalgia was reported in 14 patients out of 414 (median age was 38 years (range 19-83)) of one large registry-based study [7]. Lesions usually develop within an average of 7 days after the first dose and earlier after the booster. The common reported sites of involvement are the arms (69\%), face (31\%), hands (23\%), and feet $(15 \%)$. Farinazzo et al., Corbeddu et al., and Al-Ansari R et al. described cases of itchy acral erythema and swelling limited to the palms, hands, feet, and/or arms following the BNT162b2 vaccination in middle-aged women $[19,42,43]$.

\subsection{Urticaria/Angioedema}

Acute urticaria presenting with itchy wheals and/or angioedema can develop immediately, i.e., within hours after vaccine injection, or later, after some days [23]. Among 5574 patients receiving the first dose of BNT162b2, Bianchi et al. found that $0.1 \%$ developed urticaria or angioedema within $4 \mathrm{~h}$ [44]. Conversely, an eruption that developed after $24 \mathrm{~h}$ in $92 \%$ of the cases of urticaria reported by McCahon et al. (37) and in 93\% of the cases reported by Català et al. (29) [6,7]. Robinson et al. reported a prevalence of urticaria and angioedema following the first dose of the mRNA vaccination of $0.3 \%$ and $0.2 \%$, respectively, and $0.6 \%$ and $0.4 \%$ following the booster [8]. The recurrence of urticaria and angioedema occurred in $3.3 \%$ and $2.6 \%$ of those who experienced the first reaction, respectively. Among 803 patients receiving the BNT162b2 vaccination, Kadali et al. described wheals and angioedema of the mouth/throat in $0.6 \%$ and $0.12-0.37 \%$ of the cases, respectively [24]. Treatment with $\mathrm{H} 1$ antihistamines is generally employed successfully to resolve the lesions, and systemic glucocorticoids can be used in the case of persistence [45].

\subsection{Eczematous Dermatitis}

Diffuse or localized eczematous dermatitis in patients apparently without a history of atopic dermatitis have been reported following SARS-CoV-2 vaccination. The clinical findings are eczematous erythematous vesicular patches and papules localized on the back, arms, and legs [23,42,46] (Figure 5). Lesions tend to be bilateral but not as symmetrical as exanthematous reactions. The histopathology shows a typical spongiotic dermatitis and lympho-histiocytic infiltrate with eosinophils $[20,46]$. The administration of the second dose could be followed by the flare of eczematous lesions in those patients who experienced eczema after the first dose. Eczema can be controlled by systemic or topical glucocorticosteroids $[20,46]$. 

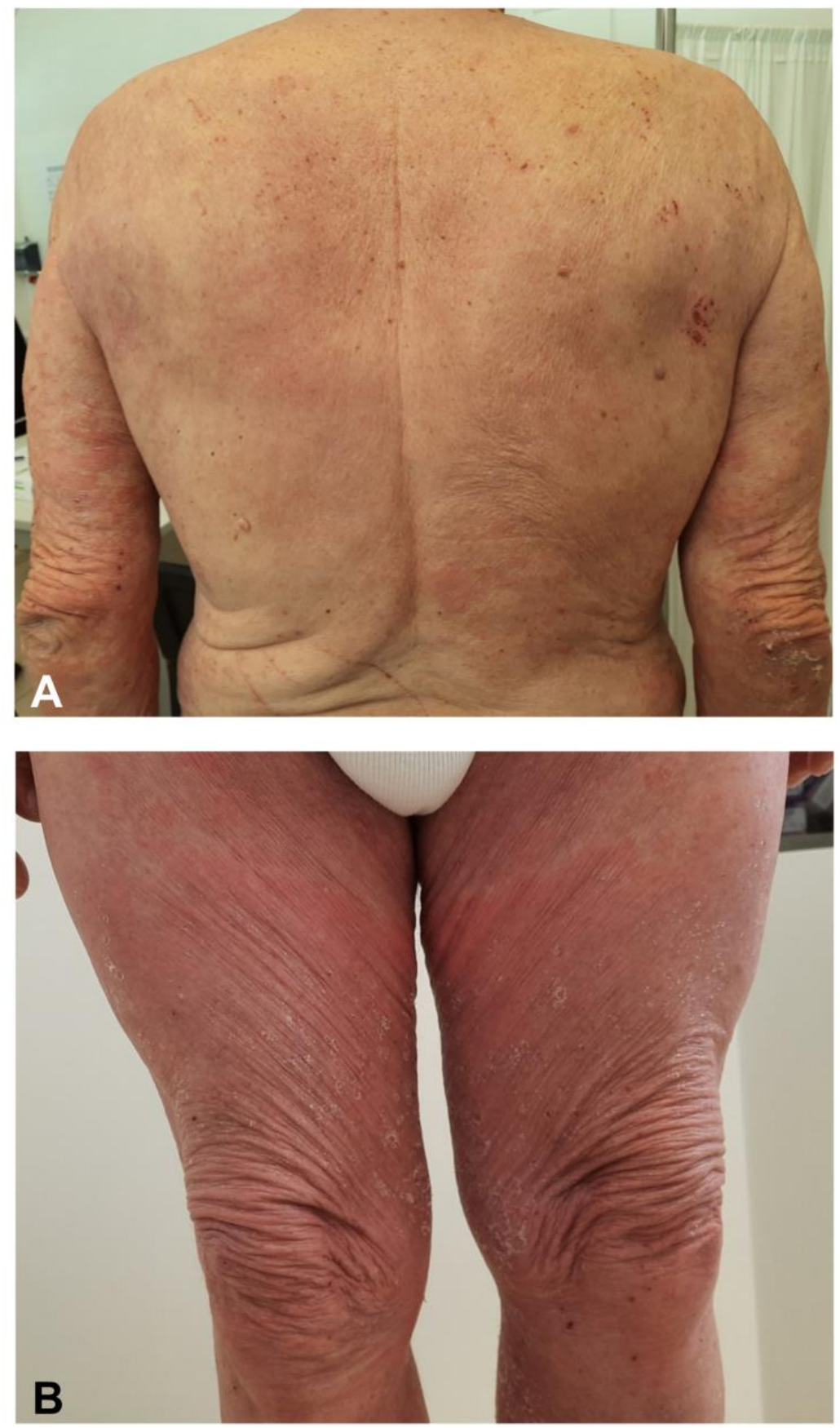

Figure 5. Diffuse bilateral eczematous lesions with overlying excoriation of the back, arms, and legs on a patient without a history of atopic dermatitis following the AZD1222 vaccine (71-year-old man) $(\mathbf{A}, \mathbf{B})$.

\subsection{Autoimmune Bullous Reactions}

Autoimmune bullous reactions following mRNA vaccines are uncommon, and few cases of autoimmune subepidermal bullous diseases have been reported. Their clinical presentations show itchy, urticated, erythematous plaques and tense bullae developing 3-21 days after the first or second dose. Most cases described fulfilled the diagnostic criteria for bullous pemphigoid or, rarely, a linear immunoglobulin A bullous dermatosis [20,47]. In a series of 12 new onset subepidermal blistering eruptions (including eight confirmed bullous pemphigoid) following the first or second dose of mRNA vaccination, the mean 
time to onset was 7 days [48]. Cases of severe pemphigus vulgaris following a few days after the BNT162b2 vaccination were also described [49].

\subsection{Severe Cutaneous Adverse Reactions (SCARs)}

Fortunately, SCARs following COVID-19 vaccinations are rare and include cases of AGEP, drug reactions with eosinophilia, and systemic symptoms (DRESS) and SJS/TEN. In these cases, no other drug-related triggers were identified. Annabi et al. reported a case of AGEP in a 43-year-old woman three days after an AstraZeneca/Oxford immunization [18]. The patient was treated with topical glucocorticosteroids with complete resolution and received a different type of vaccine (Pfizer/BioNTech) as the second dose. Lospinoso et al. described a 74-year-old man who developed a diffuse pustular rash accompanied by systemic symptoms and eosinophilia, compatible with DRESS, the day after the Janssen vaccine. The patient was treated with $20 \mathrm{mg} / \mathrm{d}$ of oral prednisone and topical glucocorticosteroids with complete remission [50]. Dash et al. reported a case of SJS in a 60-year-old man three days after the first dose of AstraZeneca/Oxford. The patient was successfully treated with $300 \mathrm{mg} /$ day of cyclosporine, with complete resolution in one week. The second dose of the vaccination was deferred [51]. Bakir et al. reported another case of TEN in a 46-year-old woman one week after the first dose of the Pfizer/BioNTech vaccine. [52]. One case of extensive erythema-multiforme in a 62-year-old man following a second dose of the Moderna vaccine was described. The patient developed erythema and blisters on the trunk, limbs, and genitalia. The blistering rash appeared after the first dose and worsened after the second dose [53]. Finally, one case of extensive bullous fixed drug eruption was reported the day after the second dose of the Moderna vaccine [54].

\subsection{Other Dermatoses}

One case of Sweet syndrome accompanied by acute encephalitis was described in a 77-year-old man after the first dose of the mRNA-1273 vaccine [55]. There are sporadic reports of fixed drug eruptions $[6,18,56]$. Two middle-aged women developed a rosacea-like eruption 4 to 5 days after Ad26.CoV2.S and BNT162b2 vaccination [57]. In some patients, COVID vaccination may induce a new onset of psoriatic disease, presenting as chronic plaque psoriasis [58,59], palmoplantar psoriasis [60], guttate psoriasis [61], generalized pustular psoriasis [62], and even pityriasis rubra pilaris [63].

\subsection{Flare of Existing Dermatoses}

Exacerbations of distinct chronic cutaneous dermatoses have been reported after the mRNA and adenovirus-vectored vaccines (Table 2). Several flares of psoriasis have been clearly documented, including cases of new onset psoriatic arthritis $[6,7,58,59]$. The development of erythematous-desquamative plaques of psoriasis after the mRNA and Ad26.CoV2.S vaccinations was described in a case series of 14 patients. Of these, nine had a preexisting history of psoriatic disease. Almost all individuals had an exacerbation of their disease relatively soon after the second vaccine dose in a mean time of 10 days [58]. Nonetheless, Kadali et al. demonstrated that, in a group of 131 patients with psoriatic arthritis, the postvaccination measures of disease activity PASI were stable in most cases [24]. However, about $20 \%$ of 117 patients had a worsening of their DAPSA score [24]. Other conditions potentially worsened by the COVID-19 vaccination are atopic dermatitis [6,20,42], lichen ruber planus [6], chronic spontaneous urticaria [64], bullous pemphigoid [65], pemphigus vulgaris [65], pityriasis rubra pilaris [66], urticarial vasculitis, cutaneous small-vessel vasculitis [67], erythema multiforme [68], and Darier's disease [69]. Finally, one case of transition from subacute cutaneous lupus erythematosus into systemic lupus erythematosus was also described [70]. Some cases of radiation recall that the phenomenon was reported 5 to 6 days after the mRNA and adenovirus-vectored vaccines. The patients showed typical acute inflammatory reactions localized to the previously irradiated skin that was successfully treated with local glucocorticosteroids [71,72]. Two cases of local Bacillus Calmette-Guérin (BCG) inflammation following mRNA vaccination were 
described $24 \mathrm{~h}$ after the second dose. Clinically, BCG inflammation presented as a painful, erythematous, and indurated plaque at the BCG scar site [73].

Table 2. Preexisting dermatoses flared by the SARS-CoV-2 vaccinations.

\begin{tabular}{ccc}
\hline Type & Subtype & Reported Associated Vaccines \\
\hline & Chronic plaque psoriasis & Pfizer/BioNTech, Moderna, \\
& Atopic dermatitis & Johnson \& Johnson/Janssen \\
Lichen ruber planus & Pfizer/BioNTech, Moderna \\
& Chronic spontaneous urticaria & Moderna \\
Bullous pemphigoid & Pfizer/BioNTech, Moderna \\
Immuno-mediated & Pemphigus vulgaris & Pfizer/BioNTech, Moderna \\
dermatoses & Pityriasis rubra pilaris & AstraZeneca/Oxford \\
& Cutaneous small-vessel & Pfizer/BioNTech \\
& vasculitis & Pfizer/BioNTech \\
& Erythema multiforme & AstraZeneca/Oxford \\
& Darier's disease & AstraZeneca/Oxford \\
& Systemic lupus erythematosus & Pfizer/BioNTech, \\
& Radiation recall phenomenon & AstraZeneca/Oxford \\
& BCG inflammation & Pfizer/BioNTech, Moderna \\
Infectious dermatoses & HSV reactivation & All \\
\hline BCG Bacillus Calmette-Guérin, HSV Herpes simplex virus, and VZV Varicella zoster virus.
\end{tabular}

Several cases of herpes simplex virus (HSV) and varicella zoster virus (VZV) reactivation have been documented [6,7,74-77]. In a large study of 405 cutaneous reactions, VZV and HSV reactivations were $10 \%$ and $3 \%$ of the cases, respectively. Herpetic reactivations developed more commonly after the first dose, with a mean time ranging from a mean 5-7 $\pm 4-6$ days (standard deviation) [6].

\section{Discussion}

Dermatologists can play an important role during the current mass vaccination campaigns addressing properly adverse cutaneous reactions secondary in the COVID-19 vaccines. The erroneous interpretation of skin reactions may expose some patients to the risk of severe reactions or may exclude some others from receiving a second dose unjustifiably. We distinguished two main categories of cutaneous reactions, flares of preexisting dermatoses and new onset reactions, and classified the latter into distinct morphological patterns. Local reactions are the commonest cutaneous reactions, particularly with mRNA-based vaccines, but they can also be elicited by adenovirus-vectored vaccines [78]. Apart from the local side effects, most cutaneous reactions secondary to SARS-CoV2 vaccination reflect those associated with COVID-19. To explain the filler reactions, it was hypothesized that the COVID-19 spike protein evokes a proinflammatory response in the location of dermal hyaluronic acid fillers through the blockade of a cutaneous ACE2 inhibitory pathway [17]. The mechanisms may involve a Th1 imbalance promoting a CD8+T-cell-mediated reaction to incipient granulomas around residual hyaluronic acid particles. Exanthemas (morbilliform or maculopapular, varicella-like, or papulovesicular); vascular lesions (purpura/petechiae, livedoid, and chilblain-like); and urticarial are morphological patterns that are already associated with SARS-CoV-2 infection [79]. Hence, common immunopathological mechanisms, including host immune activation against viral particles, rather than direct viral damage, may be involved [6,7,21]. Polyethylene glycol-2000 (PEG) and polysorbate 80 are the two main potential allergenic/immunogenic excipients in the COVID-19 vaccines. PEG-2000 is found in the Pfizer/BioNTech and Moderna vaccines and polysorbate 80 in the Oxford/AstraZeneca and Johnson \& Johnson vaccines. They may play a role in eliciting urticaria through both immediate and delayed hypersensitivity reactions [80]. Other more uncommon reactions, such as erythromelalgia and pityriasis rosea-like rash, have also been 
reported following influenza and hepatitis $B$ vaccinations. Finally, the vaccination may induce an immunomodulation that allows VZV to escape from its latent phase and elicit herpes zoster [75].

Interestingly, a higher proportion of cutaneous reactions was described in women, but it is still not clear whether this reflects a selection or publication bias or women's greater reactogenicity to vaccines $[4,6]$. According to Català et al., a history of atopy or chronic urticaria does not predispose women to SARS-CoV-2 vaccine cutaneous reactions, even if flares of the diseases are possible [6].

We found that most of the cutaneous reactions were mild, skin-limited, and characterized by a rapid resolution. Cutaneous reactions to SARS-CoV-2 vaccines reflect the patterns observed with other vaccines [33]. For example, local and delayed skin reactions, such as urticaria, maculopapular, or nonspecific skin rashes, can be commonly found after the injection of vaccines containing toxoids and the hepatitis B virus vaccine [80]. Patients with mild or moderate cutaneous reactions should undergo the second dose and, in selected cases (i.e., mastocytosis), may benefit from a prophylactic premedication (i.e., antihistamines and oral or topical glucocorticoids) [81,82]. Administering a different vaccine type for the booster dose may be reasonable to reduce the risk of relapse of the previous moderate-to-severe reactions [18]. In general, there are no contraindications to vaccinate populations with allergic diseases such as atopic dermatitis or chronic urticaria $[82,83]$. In the case of an acute flare of eczema/chronic urticaria, patients may be vigorously treated, and vaccination should not be postponed [82]. Conversely, severe reactions like SCARs and severe immediate hypersensitivity reactions (i.e., anaphylaxis) are potentially life-threatening and represent contraindications for a second vaccine dose [83,84]. It is not clear whether using a different vaccine type for the booster injection may be advisable in such cases [18] Precautions should be taken in the case of a history of anaphylaxis and in patients with systemic mastocytosis [81,84].

This review may be burdened by some limitations, including the nonsystematic method. Adverse events after SARS-CoV2 vaccination are being increasingly reported, reflecting a special interest during the pandemic. However, most of the studies are small case series burdened by publication biases that do not allow the drawing of general conclusions with high levels of evidence, such as estimating the prevalence of the different cutaneous reactions. In addition, many cases of flare-up of chronic dermatoses are not published, as the interest in the common and non-severe reactions is diminishing.

In conclusion, cutaneous reactions to the COVID-19 vaccination resemble common cutaneous drug eruptions and cutaneous manifestations of COVID-19. Dermatology's perspective on the COVID-19 mass vaccination campaign is faceted and important in order to drive clinicians to properly address vaccination cutaneous reactions and to reassure patients.

Author Contributions: Conceptualization, F.B., M.M., P.G. and G.G.; methodology, F.B.; software, F.B.; validation, P.G. and G.G.; formal analysis, M.M.; investigation, F.B.; resources, F.B.; data curation, F.B.; writing—original draft preparation, F.B.; writing—review and editing, F.B. and M.M.; visualization, M.M.; supervision, P.G. and M.M.; project administration, M.M.; funding acquisition, P.G. All authors have read and agreed to the published version of the manuscript.

Funding: This research was funded by Fondazione Cariplo and Fondazione Veronesi. Impact of COVID19 infection on patients affected by inflammatory skin diseases on immunosuppressive therapies (COVISKIN). Grant number 1833073 ref. 2020-1363.

Institutional Review Board Statement: Not applicable.

Informed Consent Statement: Not applicable.

Data Availability Statement: Data sharing not applicable.

Conflicts of Interest: The authors declare no conflict of interest. 


\section{References}

1. Chakraborty, S.; Mallajosyula, V.; Tato, C.M.; Tan, G.S.; Wang, T.T. SARS-CoV-2 vaccines in advanced clinical trials: Where do we stand? Adv. Drug Deliv. Rev. 2021, 172, 314-338. [CrossRef] [PubMed]

2. Hernández, A.F.; Calina, D.; Poulas, K.; Docea, A.O.; Tsatsakis, A.M. Safety of COVID-19 vaccines administered in the EU: Should we be concerned? Toxicol. Rep. 2021, 8, 871-879. [CrossRef] [PubMed]

3. Teijaro, J.R.; Farber, D.L. COVID-19 vaccines: Modes of immune activation and future challenges. Nat. Rev. Immunol. 2021, 21, 195-197. [CrossRef] [PubMed]

4. Castells, M.C.; Phillips, E.J. Maintaining Safety with SARS-CoV-2 Vaccines. N. Engl. J. Med. 2021, 384, 643-649. [CrossRef]

5. Blumental, S.; Debré, P. Challenges and issues of anti-SARS-CoV-2 vaccines. Front. Med. 2021, 8, 664179. [CrossRef]

6. Català, A.; Muñoz-Santos, C.; Galván-Casas, C.; Roncero Riesco, M.; Revilla Nebreda, D.; Solá-Truyols, A.; Giavedoni, M.; Llamas-Velasco, C.; González-Cruz, X.; Cubiró, R. Cutaneous reactions after SARS-COV-2 vaccination: A cross-sectional Spanish nationwide study of 405 cases. Br. J. Dermatol. 2021. Epub ahead of print. [CrossRef]

7. McMahon, D.E.; Amerson, E.; Rosenbach, M.; Lipoff, J.B.; Moustafa, D.; Tyagi, A.; Desai, S.R.; French, L.E.; Lim, H.W.; Thiers, B.H.; et al. Cutaneous reactions reported after Moderna and Pfizer COVID-19 vaccination: A registry-based study of 414 cases. J. Am. Acad. Dermatol. 2021, 85, 46-55. [CrossRef]

8. Robinson, L.B.; Fu, X.; Hashimoto, D.; Wickner, P.; Shenoy, E.S.; Landman, A.B.; Blumenthal, K.G. Incidence of Cutaneous Reactions After Messenger RNA COVID-19 Vaccines. JAMA Dermatol. 2021, 157, 1000-1002. [CrossRef]

9. Saifuddin, A.; Koesnoe, S.; Kurniati, N.; Sirait, S.; Arisanty, R.; Yunihastuti, E. COVID Arm After Moderna Booster in Healthcare Worker: A Case Report. Acta Med. Indones. 2021, 53, 326-330.

10. Samarakoon, U.; Alvarez-Arango, S.; Blumenthal, K.G. Delayed Large Local Reactions to mRNA Covid-19 Vaccines in Blacks, Indigenous Persons, and People of Color. N. Engl. J. Med. 2021, 385, 662-664. [CrossRef]

11. Fernandez-Nieto, D.; Hammerle, J.; Fernandez-Escribano, M.; Moreno-Del Real, C.M.; Garcia-Abellas, P.; Carretero-Barrio, I.; Solano-Solares, E.; de-la-Hoz-Caballer, B.; Jimenez-Cauhe, J.; Ortega-Quijano, D.; et al. Skin manifestations of the BNT162b2 mRNA COVID-19 vaccine in healthcare workers. 'COVID-arm': A clinical and histological characterization. J. Eur. Acad. Dermatol. Venereol. 2021, 35, e425-7. [CrossRef]

12. Lindgren, A.L.; Austin, A.H.; Welsh, K.M. COVID Arm: Delayed Hypersensitivity Reactions to SARS-CoV-2 Vaccines Misdiagnosed as Cellulitis. J. Prim. Care Community Health 2021, 12, 21501327211024431. [CrossRef]

13. Gruenstein, D.; Levitt, J. Skin necrosis at both COVID-19 vaccine injection sites. JAAD Case Rep. 2021, 15, 67-68. [CrossRef]

14. Blumenthal, K.G.; Freeman, E.E.; Saff, R.R.; Robinson, L.B.; Wolfson, A.R.; Foreman, R.K.; Hashimoto, D.; Banerji, A.; Li, L.; Anvari, S.; et al. Delayed Large Local Reactions to mRNA-1273 Vaccine against SARS-CoV-2. N. Engl. J. Med. 2021, 384, 1273-1277. [CrossRef]

15. Maurelli, M.; Bergamaschi, R.; Antonini, A.; Fargnoli, M.C.; Puma, E.; Mallucci, G.; Totaro, R.; Girolomoni, G. Interferon-beta injection site reactions in patients with multiple sclerosis. J. Dermatol. Treat. 2018, 29, 831-834. [CrossRef]

16. Michon, A. Hyaluronic acid soft tissue filler delayed inflammatory reaction following COVID-19 vaccination-A case report. J. Cosmet. Dermatol. 2021, 20, 2684-2690. [CrossRef]

17. Munavalli, G.G.; Guthridge, R.; Knutsen-Larson, S.; Brodsky, A.; Matthew, E.; Landau, M. “COVID-19/SARS-CoV-2 virus spike protein-related delayed inflammatory reaction to hyaluronic acid dermal fillers: A challenging clinical conundrum in diagnosis and treatment". Arch. Dermatol. Res. 2021, 1-15. [CrossRef]

18. Annabi, E.; Dupin, N.; Sohier, P.; Garel, B.; Franck, N.; Aractingi, S.; Guégan, S.; Oulès, B. Rare cutaneous adverse effects of COVID-19 vaccines: A case series and review of the literature. J. Eur. Acad. Dermatol. Venereol. 2021. [CrossRef]

19. Farinazzo, E.; Ponis, G.; Zelin, E.; Errichetti, E.; Stinco, G.; Pinzani, C.; Gambelli, A.; De Manzini, N.; Toffoli, L.; Moret, A.; et al. Cutaneous adverse reactions after m-RNA COVID-19 vaccine: Early reports from Northeast Italy. J. Eur. Acad. Dermatol. Venereol. 2021, 35, e548-e551. [CrossRef]

20. Larson, V.; Seidenberg, R.; Caplan, A.; Brinster, N.K.; Meehan, S.A.; Kim, R.H. Clinical and histopathological spectrum of delayed adverse cutaneous reactions following COVID-19 vaccination. J. Cutan. Pathol. 2021, 1-8. [CrossRef]

21. Jedlowski, P.M.; Jedlowski, M.F. Morbilliform rash after administration of Pfizer-BioNTech COVID-19 mRNA vaccine. Dermatol. Online J. 2021, 27, 13030. [CrossRef]

22. Lam, M.; Egail, M.; Bedlow, A.J.; Tso, S. Ribonucleic acid COVID-19 vaccine-associated cutaneous adverse drug events: A case series of two patients. Clin. Exp. Dermatol. 2021, 46, 1131-1134. [CrossRef]

23. Holmes, G.A.; Desai, M.; Limone, B.; Love, J.; Tawfik, M.; Wong, L.; Furukawa, B. A case series of cutaneous COVID-19 vaccine reactions at Loma Linda University Department of Dermatology. JAAD Case Rep. 2021, 16, 53-57. [CrossRef]

24. Kadali, R.A.; Janagama, R.; Peruru, S.; Malayala, S.V. Side effects of BNT162b2 mRNA COVID-19 vaccine: A randomized, cross-sectional study with detailed self-reported symptoms from healthcare workers. Int. J. Infect. Dis. 2021, 106, 376-381. [CrossRef]

25. D'Cruz, A.; Parker, H.; Saha, M. A Bullous Eruption following the Pfizer- BioNTech COVID-19 Vaccination. J. Eur. Acad. Dermatol. Venereol. 2021, 35, e864-e865. [CrossRef]

26. Cyrenne, B.; Al-Mohammedi, F.; DeKoven, J.; Alhusayen, R. Pityriasis rosea-like eruptions following vaccination with BNT162b2 mRNA COVID-19 Vaccine. J. Eur. Acad. Dermatol. Venereol. 2021, 35, e546-e548. [CrossRef] 
27. Abdullah, L.; Hasbani, D.; Kurban, M.; Abbas, O. Pityriasis rosea after mRNA COVID-19 vaccination. Int. J. Dermatol. 2021, 60, 1150-1151. [CrossRef]

28. Song, E.J.; Wong, A.J.S. Widespread annular eruption after Ad26.COV2.S COVID-19 vaccine. JAAD Case Rep. 2021, 13, 30-32. [CrossRef]

29. Guzmán-Pérez, L.; Puerta-Peña, M.; Falkenhain-López, D.; Montero-Menárguez, J.; Gutiérrez-Collar, C.; Rodríguez-Peralto, J.L.; Sanz-Bueno, J. Small-vessel vasculitis following Oxford-AstraZeneca vaccination against SARS-CoV-2. J. Eur. Acad. Dermatol. Venereol. 2021, 35, e741-e743.

30. Berry, C.T.; Eliliwi, M.; Gallagher, S.; Panaccione, S.; Klein, W.M.; Healy, A.L.; Stoecker, B.; Kallas, R. Cutaneous small vessel vasculitis following single-dose Janssen Ad26.COV2.S vaccination. JAAD Case Rep. 2021, 15, 11-14. [CrossRef] [PubMed]

31. Felicetti, P.; Trotta, F.; Bonetto, C.; Santuccio, C.; Brauchli Pernus, Y.; Burgner, D.; Chandler, R.; Girolomoni, G.; Hadden, R.D.M.; Kochhar, S.; et al. Spontaneous reports of vasculitis as an adverse event following immunization: A descriptive analysis across three international databases. Vaccine 2016, 34, 6634-6640. [CrossRef] [PubMed]

32. Guetl, K.; Gary, T.; Raggam, R.B.; Schmid, J.; Wölfler, A.; Brodmann, M. SARS-CoV-2 vaccine-induced immune thrombotic thrombocytopenia treated with immunoglobulin and argatroban. Lancet 2021, 397, e19. [CrossRef]

33. King, E.R.; Towner, E. A Case of Immune Thrombocytopenia After BNT162b2 mRNA COVID-19 Vaccination. Am. J. Case Rep. 2021, 22, e931478-1. [CrossRef] [PubMed]

34. Maayan, H.; Kirgner, I.; Gutwein, O.; Herzog-Tzarfati, K.; Rahimi-Levene, N.; Koren-Michowitz, M.; Blickstein, D. Acquired thrombotic thrombocytopenic purpura: A rare disease associated with BNT162b2 vaccine. J. Thromb. Haemost. 2021, 19, $2314-2317$. [CrossRef]

35. Yu, J.N.; Angeles, C.B.; Lim, H.G.; Chavez, C.; Roxas-Rosete, C. Cutaneous reactions to inactivated SARS-CoV-2 vaccine and ChAdOx1-S (recombinant) vaccine against SARS-CoV-2: A case series from the Philippines. J. Eur. Acad. Dermatol. Venereol. 2021, 35, e841-e845. [CrossRef]

36. Mazzatenta, C.; Piccolo, V.; Pace, G.; Romano, I.; Argenziano, G.; Bassi, A. Purpuric lesions on the eyelids developed after BNT162b2 mRNA COVID-19 vaccine: Another piece of SARS-CoV-2 skin puzzle? J. Eur. Acad. Dermatol. Venereol. 2021, 35, e543-e545. [CrossRef]

37. Pasternack, R.; Pohjavaara, S. A skin reaction with rust-like discolouration to mRNA COVID-19 vaccine. J. Eur. Acad. Dermatol. Venereol. 2021, 35, e737-e738. [CrossRef]

38. Heck, E.; Rankin, B.D.; Schneider, M.; Prajapati, V.H. Flagellate Purpura Associated With COVID-19 Vaccination. J. Eur. Acad. Dermatol. Venereol. 2021. [CrossRef]

39. Temiz, S.A.; Abdelmaksoud, A.; Dursun, R.; Vestita, M. Acral chilblain-like lesions following inactivated SARS-CoV-2 vaccination. Int. J. Dermatol. 2021, 60, 1152-1153. [CrossRef]

40. Davido, B.; Mascitti, H.; Fortier-Beaulieu, M.; Jaffal, K.; de Truchis, P. 'Blue toes' following vaccination with the BNT162b2 mRNA COVID-19 vaccine. J. Travel Med. 2021, 28, taab024. [CrossRef]

41. Pileri, A.; Guglielmo, A.; Raone, B.; Patrizi, A. Chilblain lesions after COVID-19 mRNA vaccine. Br. J. Dermatol. 2021, 185, e3. [CrossRef]

42. Corbeddu, M.; Diociaiuti, A.; Vinci, M.R.; Santoro, A.; Camisa, V.; Zaffina, S.; El Hachem, M. Transient cutaneous manifestations after administration of Pfizer-BioNTech COVID-19 Vaccine: An Italian single-centre case series. J. Eur. Acad. Dermatol. Venereol. 2021, 35, e483-e485. [CrossRef]

43. Al-Ansari, R.Y.; Al-Sharari, M.; Al-Saadi, T. Palms and soles itchiness as a side effect of COVID-19 vaccination. J. Infect. Public Health 2021, 14, 1389-1391. [CrossRef]

44. Bianchi, L.; Biondi, F.; Hansel, K.; Murgia, N.; Tramontana, M.; Stingeni, L. Skin tests in urticaria/angioedema and flushing to Pfizer-BioNTech SARS-CoV-2 vaccine: Limits of intradermal testing. Allergy 2021, 76, 2605-2607. [CrossRef]

45. Weinstock-Guttman, B.; Jakimovski, D. Late-onset cutaneous reaction to BNT162b2 mRNA COVID-19 vaccine in an immunocompromised patient. Mult. Scler. 2021. [CrossRef]

46. Leasure, A.C.; Cowper, S.E.; McNiff, J.; Cohen, J.M. Generalized eczematous reactions to the Pfizer-BioNTech COVID-19 vaccine. J. Eur. Acad. Dermatol. Venereol. 2021. [CrossRef]

47. Coto-Segura, P.; Fernández-Prada, M.; Mir-Bonafé, M.; García-García, B.; González-Iglesias, I.; Alonso-Penanes, P.; González-Guerrero, M.; Gutiérrez-Palacios, A.; Miranda-Martínez, E.; Martinón-Torres, F. Vesicolous-bullous skin reactions induced by COVID-19 mRNA vaccine: Report of four cases and review of the literature. Clin. Exp. Dermatol. 2021. [CrossRef]

48. Tomayko, M.M.; Damsky, W.; Fathy, R.; McMahon, D.E.; Turner, N.; Valentin, M.N.; Rallis, T.; Aivaz, O.; Fox, L.P.; Freeman, E.E. Subepidermal blistering eruptions, including bullous pemphigoid, following COVID-19 vaccination. J. Allergy Clin. Immunol. 2021, 148, 750-751. [CrossRef]

49. Solimani, F.; Mansour, Y.; Didona, D.; Dilling, A.; Ghoreschi, K.; Meier, K. Development of severe pemphigus vulgaris following SARS-CoV-2 vaccination with BNT162b2. J. Eur. Acad. Dermatol. Venereol. 2021, 35, e649. [CrossRef]

50. Lospinoso, K.; Nichols, C.S.; Malachowski, S.J.; Mochel, M.C.; Nutan, F. A case of severe cutaneous adverse reaction following administration of the Janssen Ad26.COV2.S COVID-19 vaccine. JAAD Case Rep. 2021, 13, 134-137. [CrossRef]

51. Dash, S.; Sirka, C.S.; Mishra, S.; Viswan, P. COVID-19 vaccine-induced Stevens-Johnson syndrome. Clin. Exp. Dermatol. 2021. [CrossRef] 
52. Bakir, M.; Almeshal, H.; Alturki, R.; Obaid, S.; Almazroo, A. Toxic Epidermal Necrolysis Post COVID-19 Vaccination-First Reported Case. Cureus 2021, 13, e17215. [CrossRef]

53. Khalid, M.; Lipka, O.; Becker, C. Moderna COVID-19 Vaccine Induced Skin Rash. Vis. J. Emerg. Med. 2021, 25, 101108. [CrossRef]

54. Kong, J.; Cuevas-Castillo, F.; Nassar, M.; Lei, C.M.; Idrees, Z.; Fix, W.C.; Halverstam, C.; Mir, A.; Elbendary, A.; Mathew, A. Bullous drug eruption after second dose of mRNA-1273 (Moderna) COVID-19 vaccine: Case report. J. Infect. Public Health 2021, 14, 1392-1394. [CrossRef]

55. Torrealba-Acosta, G.; Martin, J.C.; Huttenbach, Y.; Garcia, C.R.; Sohail, M.R.; Agarwal, S.K.; Wasko, C.; Bershad, E.M.; Hirzallah, M.I. Acute encephalitis, myoclonus and Sweet syndrome after mRNA-1273 vaccine. BMJ Case Rep. 2021, 14, e243173. [CrossRef]

56. Mintoff, D.; Pisani, D.; Betts, A.; Scerri, L. SARS-CoV-2 mRNA vaccine-associated fixed drug eruption. J. Eur. Acad. Dermatol. Venereol. 2021, 35, e560-e563. [CrossRef]

57. Ciccarese, G.; Drago, F.; Rebora, A.; Parodi, A. Two cases of papulo-pustular rosacea-like eruptions following COVID-19 vaccinations. J. Eur. Acad. Dermatol. Venereol. 2021. [CrossRef]

58. Sotiriou, E.; Tsentemeidou, A.; Bakirtzi, K.; Lallas, A.; Ioannides, D.; Vakirlis, E. Psoriasis exacerbation after COVID-19 vaccination: A report of 14 cases from a single centre. J. Eur. Acad. Dermatol. Venereol. 2021, 35, e857-e859. [CrossRef]

59. Krajewski, P.K.; Matusiak, Ł.; Szepietowski, J.C. Psoriasis flare-up associated with second dose of Pfizer-BioNTech BNT16B2b2 COVID-19 mRNA vaccine. J. Eur. Acad. Dermatol. Venereol. 2021, 35, e632-e634. [CrossRef]

60. Quattrini, L.; Verardi, L.; Caldarola, G.; Peluso, G.; De Simone, C.; D'Agostino, M. New onset of remitting seronegative symmetrical synovitis with pitting oedema and palmoplantar psoriasis flare-up after Sars-Cov-2 vaccination. J. Eur. Acad. Dermatol. Venereol. 2021, 35, e727-e729. [CrossRef]

61. Lehmann, M.; Schorno, P.; Hunger, R.E.; Heidemeyer, K.; Feldmeyer, L.; Yawalkar, N. New onset of mainly guttate psoriasis after COVID-19 vaccination: A case report. J. Eur. Acad. Dermatol. Venereol. 2021, 35, e752-e755. [CrossRef] [PubMed]

62. Elamin, S.; Hinds, F.; Tolland, J. A case of de novo generalised pustular psoriasis following Oxford-AstraZeneca COVID-19 Vaccine. Clin. Exp. Dermatol. 2021. [CrossRef]

63. Hunjan, M.K.; Roberts, C.; Karim, S.; Hague, J. Pityriasis rubra pilaris-like eruption following administration of the BNT163b2 (Pfizer-BioNTech) mRNA COVID-19 vaccine. Clin. Exp. Dermatol. 2021. [CrossRef] [PubMed]

64. Alflen, C.; Birch, K.; Shilian, R.; Wu, S.S.; Hostoffer, R., Jr. Two Cases of Well Controlled Chronic Spontaneous Urticaria Triggered by the Moderna COVID-19 Vaccine. Allergy Rhinol. 2021, 12, 21526567211026271. [CrossRef] [PubMed]

65. Damiani, G.; Pacifico, A.; Pelloni, F.; Iorizzo, M. The first dose of COVID-19 vaccine may trigger pemphigus and bullous pemphigoid flares: Is the second dose therefore contraindicated? J. Eur. Acad. Dermatol. Venereol. 2021, 35, e645. [CrossRef] [PubMed]

66. Sahni, M.K.; Roy, K.; Asati, D.P.; Khurana, U. An old entity, a new trigger: Post COVID-19 vaccine Pityriasis rubra pilaris. Int. J. Risk Saf. Med. 2021, 1-4, preprint. [CrossRef] [PubMed]

67. Cohen, S.R.; Prussick, L.; Kahn, J.S.; Gao, D.X.; Radfar, A.; Rosmarin, D. Leukocytoclastic vasculitis flare following the COVID-19 vaccine. Int. J. Dermatol. 2021, 60, 1032-1033. [CrossRef]

68. Lavery, M.J.; Nawimana, S.; Parslew, R.; Stewart, L. A flare of pre-existing erythema multiforme following BNT162b2 (PfizerBioNTech) COVID-19 vaccine. Clin. Exp. Dermatol. 2021, 46, 1325-1327. [CrossRef]

69. Elbæk, M.V.; Vinding, G.R.; Jemec, G.B.E. Darier's Disease Flare following COVID-19 Vaccine. Case Rep. Dermatol. 2021, 13, 432-436. [CrossRef]

70. Kreuter, A.; Burmann, S.N.; Burkert, B.; Oellig, F.; Michalowitz, A.L. Transition of cutaneous into systemic lupus erythematosus following adenoviral vector-based SARS-CoV-2 vaccination. J. Eur. Acad. Dermatol. Venereol. 2021, 35, e733-e735. [CrossRef]

71. Soyfer, V.; Gutfeld, O.; Shamai, S.; Schlocker, A.; Merimsky, O. COVID-19 Vaccine-Induced Radiation Recall Phenomenon. Int. J. Radiat. Oncol. Biol. Phys. 2021, 110, 957-961. [CrossRef]

72. Stewart, R.; McDowell, L. Radiation Recall Phenomenon Following COVID-19 Vaccination. Int. J. Radiat. Oncol. Biol. Phys. 2021, 111, 835-836. [CrossRef]

73. Lopatynsky-Reyes, E.Z.; Acosta-Lazo, H.; Ulloa-Gutierrez, R.; Ávila-Aguero, M.L.; Chacon-Cruz, E. BCG Scar Local Skin Inflammation as a Novel Reaction Following mRNA COVID-19 Vaccines in Two International Healthcare Workers. Cureus 2021, 13, e14453. [CrossRef]

74. Vastarella, M.; Picone, V.; Martora, F.; Fabbrocini, G. Herpes zoster after ChAdOx1 nCoV-19 vaccine: A case series. J. Eur. Acad. Dermatol. Venereol. 2021, 35, e845-e846. [CrossRef]

75. Özdemir, A.K.; Kayhan, S.; Çakmak, S.K. Herpes zoster after inactivated SARS-CoV-2 vaccine in two healthy young adults. J. Eur. Acad. Dermatol. Venereol. 2021, 35, e846-e847. [CrossRef]

76. David, E.; Landriscina, A. Herpes Zoster Following COVID-19 Vaccination. J. Drugs Dermatol. 2021, 20, 898-900.

77. Santovito, L.S.; Pinna, G. A case of reactivation of varicella-zoster virus after BNT162b2 vaccine second dose? Inflamm. Res. 2021, 70, 935-937. [CrossRef]

78. Sprute, R.; Schumacher, S.; Pauls, M.; Pauls, W.; Cornely, O.A. Delayed Cutaneous Hypersensitivity Reaction to Vaxzevria (ChAdOx1-S) Vaccine against SARS-CoV-2. Drugs $R$ D 2021, 1-4. [CrossRef]

79. Gisondi, P.; PIaserico, S.; Bordin, C.; Alaibac, M.; Girolomoni, G.; Naldi, L. Cutaneous manifestations of SARS-CoV-2 infection: A clinical update. J. Eur. Acad. Dermatol. Venereol. 2020, 34, 2499-2504. [CrossRef] 
80. Caubet, J.C.; Ponvert, C. Vaccine allergy. Immunol. Allergy Clin. N. Am. 2014, 34, 597-613. [CrossRef]

81. Bonadonna, P.; Brockow, K.; Niedoszytko, M.; Elberink, H.O.; Akin, C.; Nedoszytko, B.; Butterfield, J.H.; Alvarez-Twose, I.; Sotlar, K.; Schwaab, J.; et al. COVID-19 Vaccination in Mastocytosis: Recommendations of the European Competence Network on Mastocytosis (ECNM) and American Initiative in Mast Cell Diseases (AIM). J. Allergy Clin. Immunol. Pract. 2021, 9, $2139-2144$. [CrossRef]

82. Ring, J.; Worm, M.; Wollenberg, A.; Thyssen, J.P.; Jakob, T.; Klimek, L.; Bangert, C.; Barbarot, S.; Bieber, T.; de Bruin-Weller, M.S.; et al. Risk of severe allergic reactions to COVID-19 vaccines among patients with allergic skin diseases-Practical recommendations. A position statement of ETFAD with external experts. J. Eur. Acad. Dermatol. Venereol. 2021, 35, e362-e365. [CrossRef]

83. Kim, M.A.; Lee, Y.W.; Kim, S.R.; Kim, J.H.; Min, T.K.; Park, H.S.; Shin, M.; Ye, Y.M.; Lee, S.; Lee, J.; et al. COVID-19 Vaccineassociated Anaphylaxis and Allergic Reactions: Consensus Statements of the KAAACI Urticaria/Angioedema/Anaphylaxis Working Group. Allergy Asthma Immunol. Res. 2021, 13, 526-544. [CrossRef]

84. Centers for Disease Control and Prevention. What to Do If You Have an Allergic Reaction After Getting a COVID-19 Vaccine. 2021. Available online: https://www.cdc.gov/coronavirus/2019-ncov/vaccines/safety/allergic-reaction.html (accessed on 27 October 2021). 